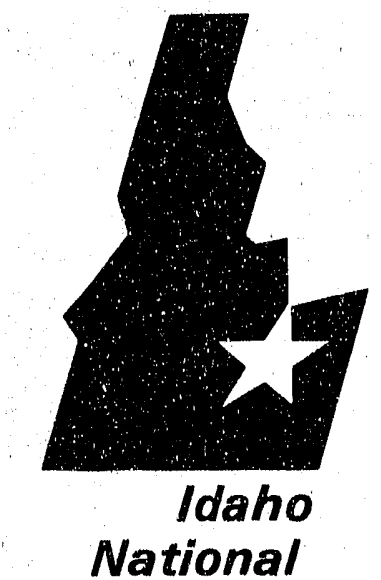

Engineering Laboratory

Managed

by the U.S.

Department

of Energy
EGG-WTD-9872

November 1991

APR a 7190

Parametric Melting Studies For In Situ Vitrification

INFORMAL REPORT

\author{
M. O. Fryer
G. L. Hawkes
P. E. Murray \\ M. O. Fryer
G. L. Hawkes
P. E. Murray \\ M. O. Fryer
G. L. Hawkes
P. E. Murray
}

$\operatorname{lichar}_{\text {idaho }}$

Work performed under
DOE Contract No. DE-ACO7-761D01570 
This document contains new concepts or the author(s) interpretation of new calculations and/or measurements; accordingly, EG\&G Idaho, Inc. is required by the United States Government to include the following disclaimer:

\section{DISCLAIMER}

This report was prepared as an account of work sponsored by an agency of the United States Government. Neither the United States Government nor any agency thereof, nor any of their amployees, makes any warranty, express or implied, or assumes any legal liability or responsibility for the accuracy, completeness, or usefulness of any iniormation, apparatus, product or process disclosed, or represents that its use would not infringe privately owned rights. References herein to any specific commercial product, process, or service by trade name, trademark, manufacturer, or otherwise, does not necessarily constitute or imply its endorsement, recommendation, or favoring by the United States Government or any agency thereot. The views and opinions of authors expressed herein do not necessarily state or reflect those of the United States Government or any agency thereof. 


\title{
PARAMETRIC MELTING STUDIES FOR IN SITU VITRIFICATION
}

\author{
M. O. Fryer \\ G. L. Hawkes \\ P. E. Murray
}

Published November 1991

Idaho National Engineering Laboratory

EG\&G Idaho, Inc.

Idaho Falls, Idaho 83415

Prepared for the

U.S. Department of Energy

Office of Environmental Restoration and Waste Management

Under DOE Field Office, Idaho

Contract DE-AC07-76ID01570 
EGG-WTD-9872

PARAMETRIC MELTING STUDIES FOR IN SITU VITRIFICATION

Reviewed by:
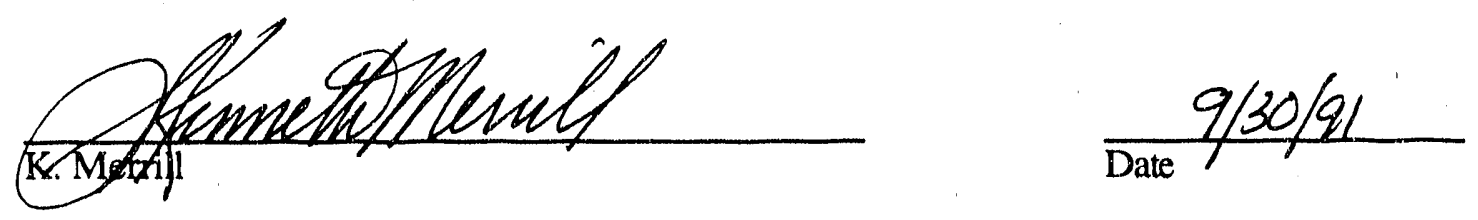

Prepared by:

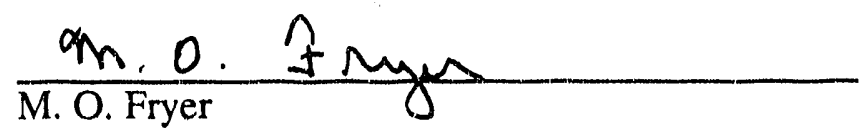

$$
\frac{9-24-91}{\text { Date }}
$$
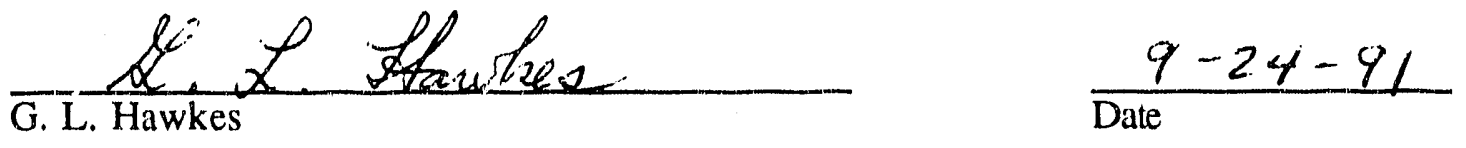

P. E. Murray

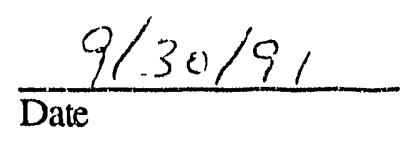




\section{ABSTRACT}

This report describes a series of simulation studies which examine heat conduction and electric heating during in situ vitrification (ISV). The simulation studies determine the effects of soil parameter changes on the ISV process. Changes in heat capacity, thermal conductivity and electrical conductivity are considered. The results of these studies provide a basis for experimental measurement accuracy requirements. 


\section{CONTENTS}

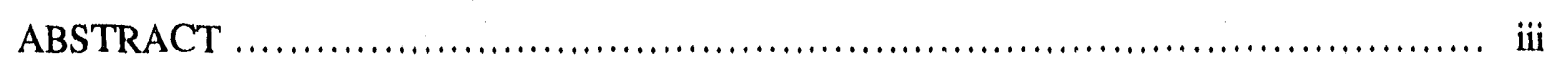

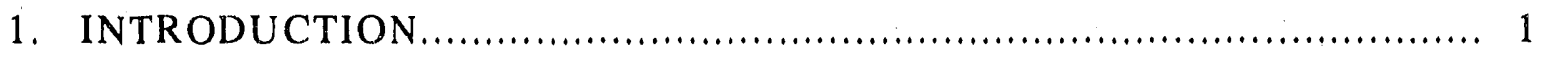

2. COMPUTATIONAL SOFTWARE................................................ 2

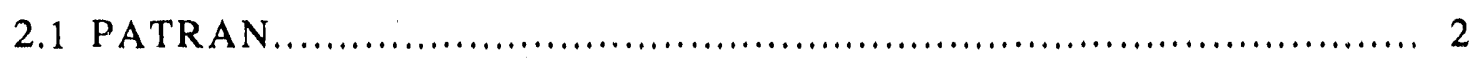

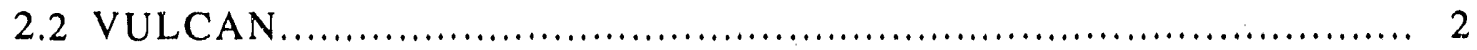

3. PROBLEM DESCRIPTION............................................... 3

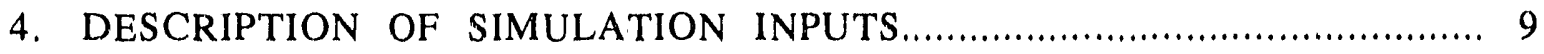

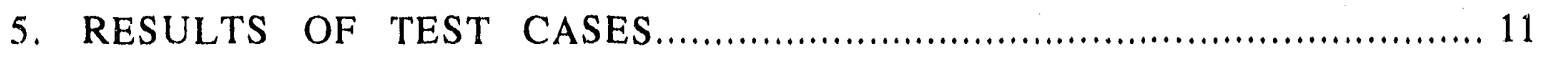

5.1 Melt Volume Comparison............................................... 11

5.2 Melt Volume Sensitivity to Soil Parameters......................................... 11

5.3 Importance of High and Low Temperature Values of Soil Parameters................. 15

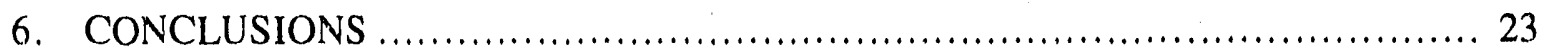

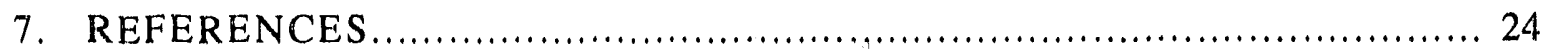




\section{FIGURES}

1. One-quarter ISV model description......................................... 4

2. Finite element mesh for base and slow cases .................................... 7

3. Finite element mesh for fast case .............................................. 8

4. Melt volume cross sections..................................................... 12

5. Melt volumes for basic scenarios.................................................. 13

6. Percent difference in melt volume .............................................. 14

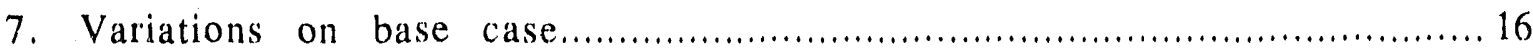

8. Change in melt volume for base case ......................................... 17

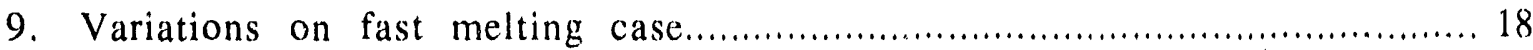

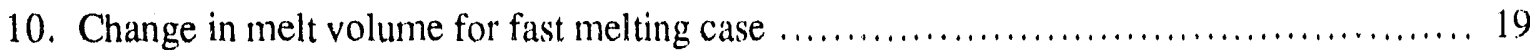

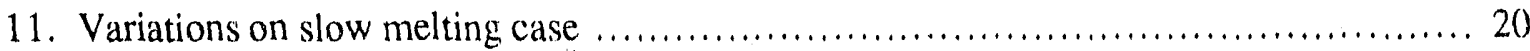

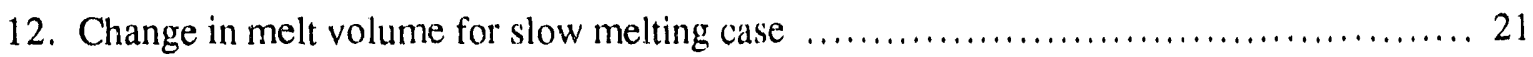

\section{TABLES}

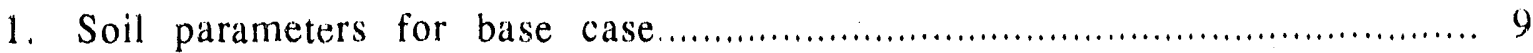

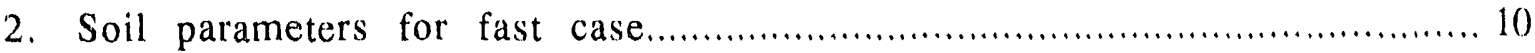

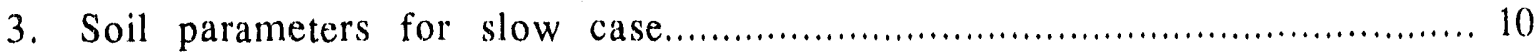




\section{PARAMETRIC MELTING STUDIES FOR IN SITU VITRIFICATION}

\section{INTRODUCTION}

This report presents numerical studies performed in support of the Idaho National Engineering Laboratory (INEL) In Situ Vitrification (ISV) treatability study. These studies include heat transport and melting during the ISV process. The ISV process results are dependent on the properties of the soil that is melted. This report describes a series of simulations that quantify how the ISV melt volume changes with soil parameters. The basic soil parameters determining how the soil melts are heat capacity, thermal conductivity, heat of fusion, and electrical conductivity.

The studies presented here were performed with the PATRAN ${ }^{1}$ and VULCAN ${ }^{2}$ computer codes. The finite element mesh generator PATRAN was used to create the finite element models. The finite element code VULCAN was used to simulate the ISV process. VULCAN solves the coupled electric field and heat transport equations. These codes are described in Section 2. A description of the problem solved is given in Section 3. Soil parameters used for the study are described in Section 4. Results of the ISV simulation are given in Section 5 and Section 6 is the Conclusion. 


\section{COMPUTATIONAL SOFTWARE}

The computer codes PATRAN and VULCAN are described in the iollowing sections. The codes are discussed in order of their general use.

\subsection{PATRAN}

PATRAN is a general purpose, three-dimensional computer-aided engineering software system. It includes capabilities for generating finite element meshes in cartesian, cylindrical, or spherical coordinate systems, using automated command sequences. Element material properties, surface heat flux values, convection heat transfer coefficients for element faces, electric field boundary conditions, and temperature initial conditions may be specified. PATRAN was used to generate finite element meshes for the models described in this report. The PATRAN-generated meshes were verified by inspecting the nodalization and boundary conditions prior to each use. PATRAN was also used as a pre- and post-processor for VULCAN.

\subsection{VULCAN}

VULCAN is a finite element code used to solve three-dimensional transient heat conduction and electric field equations. Steady-state electric field solutions are obtained by direct integration of the electric potential equation. Transient temperature solutions are obtained by integrating the transient heat conduction equation with backward difference time integration. VULCAN uses an adaptive time stepping algorithm to automatically choose the time step. A user-supplied tolerance on the maximum temperature change allowed in a time increment is used to adjust the time step. This approach was taken to conserve on computation time while allowing VULCAN to adapt to rapid changes in the solution.

VULCAN was used to analyze transient heat conduction and Joule heating of the ISV process. Inputs used to simulate the ISV process are heat capacity, thermal conductivity and electrical conductivity as functions of temperature. 


\section{PROBLEM DESCRIPTION}

A region of soil is considered whose geometry is illustrated in Figure 1. The calculation is performed in a cartesian coordinate system $(x, y, z)$. One-quarter of a four electrode ISV model is used since symmetry can be assumed for the temperature and electric fields. The electrodes have a $3 \mathrm{~m}$ spacing and are $0.33 \mathrm{~m}$ square. The assumption is made that there is initially a small square region between the electrodes in which the soil is at its melting temperature. The initial melt zone extending between the electrodes is $30-\mathrm{cm}$ thick and covered with $10 \mathrm{~cm}$ of soil. The rest of the soil is initially at ambient temperature.

As a result of electrical resistance heating, the soil temperature increases above the melting point. Heat energy is lost at the ground surface to the air by radiation. The other five surfaces of the region are assumed to be adiabatic since the external surfaces are far from the heat source and the interior surfaces have no net heat flux by symmetry. The boundary conditions and initial conditions of the problem are also illustrated in Figure 1.

An initial voltage of $2930 \mathrm{~V}$ is applied to the entire fixed electrode to start the simulation. Two electric fields need to be solved. For the first electric field a positive voltage is applied to electrodes one and two (electrode number one is shown in Figure 1) and a negative voltage is applied to electrodes three and four. For the second electric field a positive voltage is applied to electrodes two and three and a negative voltage is applied to electrodes one and four. The electrodes in the preceding example are numbered in a clockwise fashion. For the first electric field a voltage boundary condition of zero is applied on one of the interior faces of the model, while the other five surfaces are zero electric field $\left(\partial \phi_{1} / \partial n=0\right)$. The same boundary conditions are applied for the second electric field except the zero voltage boundary condition is applied to the other interior face.

The governing equation to solve the electric potentials $\left(\phi_{1}\right.$ and $\left.\phi_{2}\right)$ is given by

$$
\frac{\partial}{\partial \mathbf{x}}\left(\mathbf{k}_{\phi}(\mathrm{T}) \frac{\partial \phi_{1,2}}{\partial \mathbf{x}}\right)+\frac{\partial}{\partial \mathbf{y}}\left(\mathbf{k}_{\phi}(\mathrm{T}) \frac{\partial \phi_{1,2}}{\partial \mathbf{y}}\right)+\frac{\partial}{\partial z}\left(\mathbf{k}_{\phi}(T) \frac{\partial \phi_{1,2}}{\partial z}\right)=0
$$




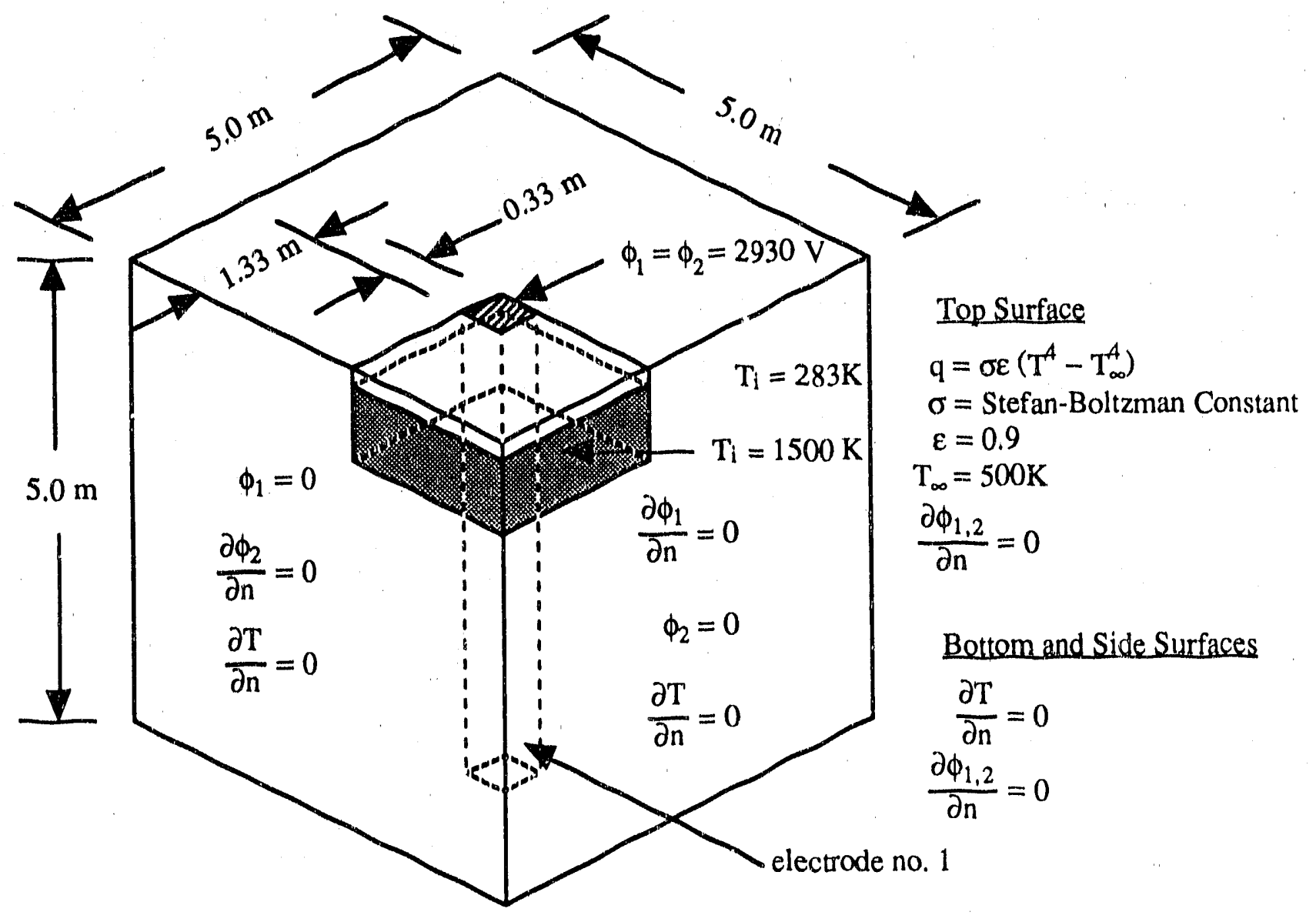

Figure 1. One-quarter ISV model description. 
where

$$
\begin{array}{ll}
\phi_{1}(\mathrm{x}, \mathrm{y}, \mathrm{z}) & =\text { first electric potential } \\
\phi_{2}(\mathrm{x}, \mathrm{y}, \mathrm{z}) & =\text { second electric potential } \\
\mathrm{k}_{\phi} & =\text { electrical conductivity } \\
\mathrm{T} & =\text { temperature. }
\end{array}
$$

The governing equation of heat conduction is given by

$\rho c_{p} \frac{\partial T}{\partial t}-\frac{\partial}{\partial x}\left(k(T) \frac{\partial T}{\partial x}\right)-\frac{\partial}{\partial y}\left(k(T) \frac{\partial T}{\partial y}\right)-\frac{\partial}{\partial z}\left(k(T) \frac{\partial T}{\partial z}\right)=Q(T)$

where

$$
\begin{array}{ll}
\mathrm{T}(\mathrm{x}, \mathrm{y}, \mathrm{z}, \mathrm{t}) & =\text { temperature } \\
\mathrm{t} & =\text { time } \\
\rho & =\text { density } \\
\mathrm{c}_{\mathrm{p}} & =\text { specific heat } \\
\mathrm{k} & =\text { thermal conductivity } \\
\mathrm{Q} & =\text { electrical heat source given by the following equation: }
\end{array}
$$

$$
\mathbf{Q}(\mathbf{T})=\frac{\mathbf{k}_{\phi}(T)}{2}\left\{\left[\left(\frac{\partial \phi_{1}}{\partial \mathbf{x}}\right)^{2}+\left(\frac{\partial \phi_{1}}{\partial \mathbf{y}}\right)^{2}+\left(\frac{\partial \phi_{1}}{\partial \mathbf{z}}\right)^{2}\right]+\left[\left(\frac{\partial \phi_{2}}{\partial \mathbf{x}}\right)^{2}+\left(\frac{\partial \phi_{2}}{\partial \mathbf{y}}\right)^{2}+\left(\frac{\partial \phi_{2}}{\partial \mathbf{z}}\right)^{2}\right]\right\}
$$

A total power of $0.2 \mathrm{MW}$ for the one-quarter model was input into the soil. In order to maintain $0.2 \mathrm{MW}$ of power in the model a varying voltage boundary condition at the electrode was implemented and maintained by

$\phi_{(1,2)_{1}}=\phi_{(1,2)_{1-1}} \sqrt{\frac{\mathbf{P}_{\mathrm{d}}}{\mathbf{P}_{\mathrm{i}-1}}}$

where

$$
\begin{aligned}
& \mathrm{i}=\text { current time step } \\
& \mathrm{P}_{\mathrm{d}}=\text { desired power of } 0.2 \mathrm{MW} \\
& \mathrm{P}_{\mathrm{i}-1}=\text { power at the previous time step given by the following equation: }
\end{aligned}
$$




$$
P_{i-1}=\frac{\sum_{j=1}^{n e l m} Q_{j, i-1}(T) V_{o l}}{\sum_{j=1}^{n e ! m} V_{j} l_{j}}
$$

where

$$
\begin{array}{ll}
\text { nelm } & =\text { total number of elements } \\
j & =\text { element number } \\
\text { Vol } & =\text { jth element volume. }
\end{array}
$$

Three cases were simulated in this analysis: (a) base case, (b) fast case, and (c) slow case. The finite element mesh for the base case and slow case simulations is shown in Figure 2. The mesh has a fine spacing near the electrodes. There are 2904 elements with eight nodes per element. The electrodes are $1 / 3 \mathrm{~m} \times 1 / 3 \mathrm{n}$ and are represented with four elements. Figure 3 shows the finite element mesh used for the fast case. A larger mesh is needed to avoid an increase in temperatures at the mesh boundaries during simulation. The mesh has a radius of $8 \mathrm{~m}$ in the $\mathrm{x}$ and $y$ directions with a height of $10 \mathrm{~m}$ in the $\mathrm{z}$ direction. There are 4725 eight-noded elements in the mesh. The electrode sizes and boundary conditions are the same as the square mesh. 


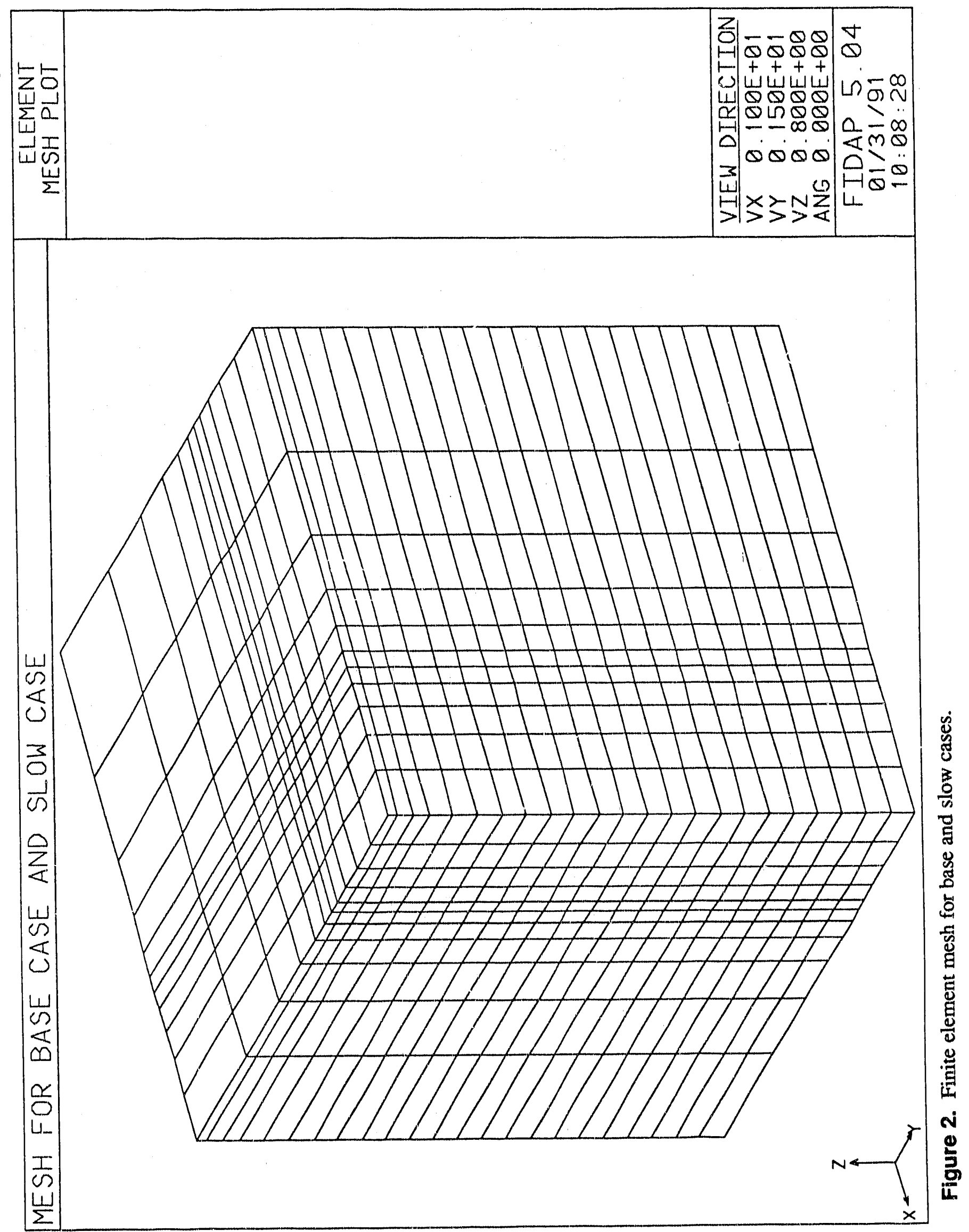



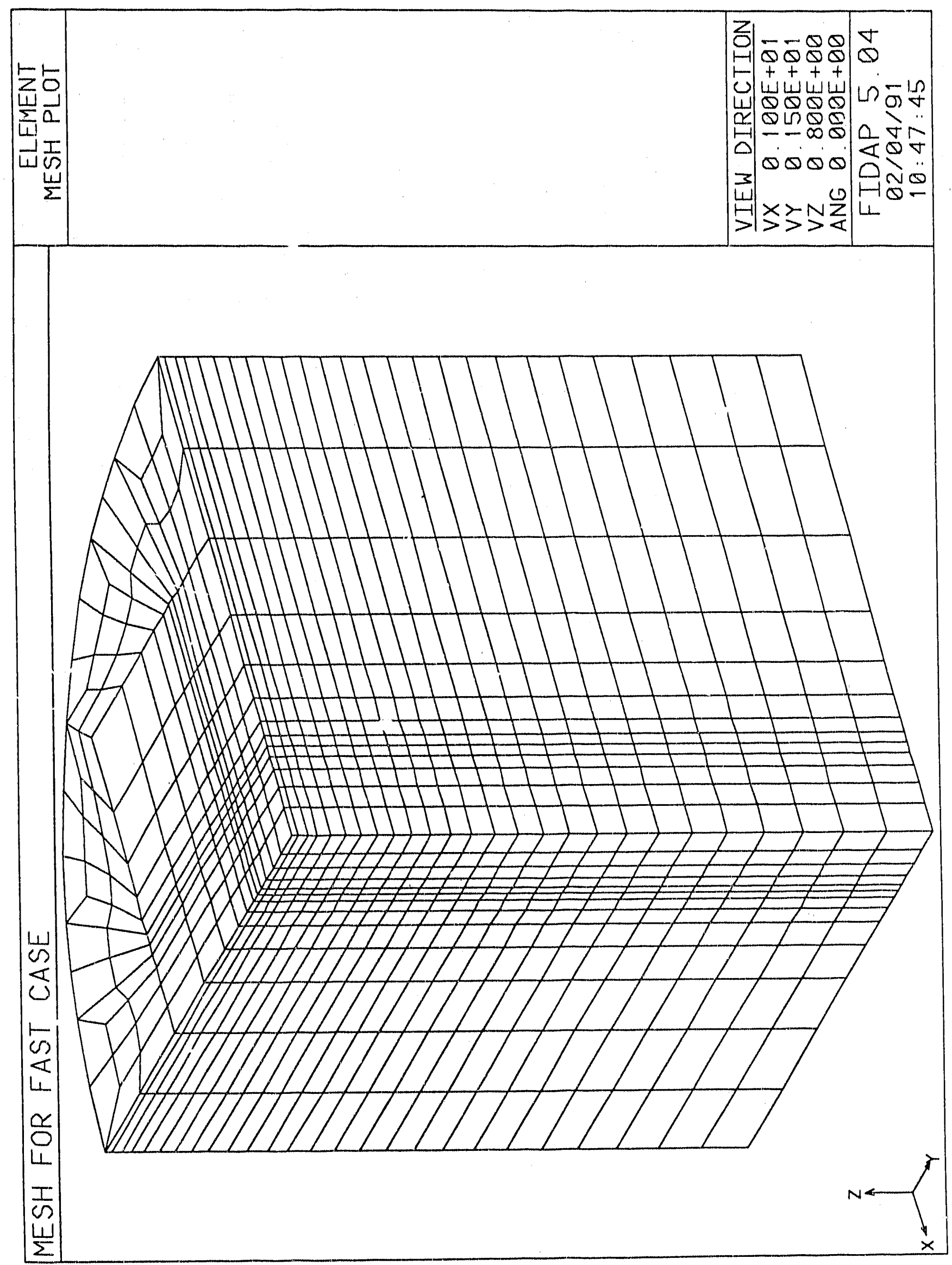

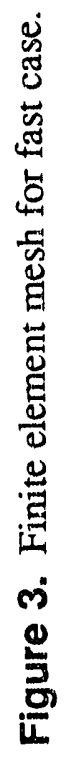




\section{DESCRIPTION OF SIMULATION INPUTS}

The scenarios selected for this report are a base case that uses average soil parameters from Reference 3, a fast melting case, and a slow melting case. For the fast melting case, soil parameters are changed by $50 \%$ so that considerably faster melting occurs. For the slow melting case, soil parameters are changed by $50 \%$ in the opposite direction so that slower melting occurs. Electrical power of $0.8 \mathrm{MW}$ was applied to the soil in all three scenarios. These three scenarios are described in the following paragraphs.

The soil parameters used in the base case scenario are shown in Table 1. The latent heat of fusion and melting temperature are $2.5 \mathrm{E}+5$ Joules and $1473 \mathrm{~K}$, respectively. For electrical conductivity, average soil values are taken from Reference 3 . The electrical conductivity for the highest temperature is an extrapolation of the measured conductivities. Thermal conductivity for a Hanford soil was taken from Reference 3 . The thermal conductivity for the highest temperatures is an extrapolation from the measured values. A typical high temperature soil specific heat value is taken from Reference 3.

Table 1. Soil parameters for base case

\begin{tabular}{|c|c|c|c|}
\hline $\begin{array}{c}\text { Temperature } \\
(\mathrm{K})\end{array}$ & $\begin{array}{c}\mathrm{cp}_{\mathrm{p}} \\
(\mathrm{J} / \mathrm{kg}-\mathrm{K}) \\
\end{array}$ & $\begin{array}{c}k \\
(W / m-K) \\
\end{array}$ & $\begin{array}{c}\mathrm{k}_{\phi} \\
(1 / \mathrm{ohm}-\mathrm{m}) \\
\end{array}$ \\
\hline $\begin{array}{r}273 \\
1273 \\
1473 \\
2503\end{array}$ & $\begin{array}{l}1000 \\
1000 \\
1000 \\
1000\end{array}$ & $\begin{array}{r}0.1 \\
1.0 \\
8.0 \\
38.0\end{array}$ & $\begin{array}{l}0.0001 \\
0.8 \\
2.0 \\
26.0\end{array}$ \\
\hline
\end{tabular}

The soil parameters used in the fast melting case scenario are shown in Table 2. As compared with the base case, specific heat is $50 \%$ lower and the thermal and electrical conductivities are $50 \%$ higher. 
Table 2. Soil parameters for fast case

\begin{tabular}{|c|c|c|c|}
\hline $\begin{array}{l}\text { Temperature } \\
\text { (K) }\end{array}$ & $\begin{array}{c}c_{p} \\
(J / k g-K)\end{array}$ & $\begin{array}{c}k \\
(W / m-K) \\
\end{array}$ & $\begin{array}{c}\mathrm{k}_{\phi} \\
\text { (1/ohm-m) }\end{array}$ \\
\hline $\begin{array}{r}273 \\
1273 \\
1473 \\
2503\end{array}$ & $\begin{array}{l}500 \\
500 \\
500 \\
500\end{array}$ & $\begin{array}{l}0.15 \\
1.5 \\
12.0 \\
57.0\end{array}$ & $\begin{array}{l}0.00015 \\
1.2 \\
3.0 \\
39.0\end{array}$ \\
\hline
\end{tabular}

The soil parameters used in the slow melting case scenario are shown in Table 3. As compared with the base case, specific heat is $50 \%$ higher and the thermal and electrical conductivities are $50 \%$ lower.

Table 3. Soil parameters for slow case

\begin{tabular}{cccc}
\hline $\begin{array}{c}\text { Temperature } \\
(\mathrm{K})\end{array}$ & $\begin{array}{c}\mathrm{c}_{\mathrm{p}} \\
(\mathrm{J} / \mathrm{kg}-\mathrm{K})\end{array}$ & $\begin{array}{c}\mathrm{k} \\
(\mathrm{W} / \mathrm{m}-\mathrm{K})\end{array}$ & $\begin{array}{c}\mathrm{k}_{\phi} \\
(1 / \mathrm{ohm}-\mathrm{m})\end{array}$ \\
\cline { 3 - 4 } 273 & 1500 & 0.05 & $5 \mathrm{E}-05$ \\
1273 & 1500 & 0.5 & 0.4 \\
1473 & 1500 & 4.0 & 1.0 \\
2503 & 1500 & 19.0 & 13.0 \\
\hline
\end{tabular}




\section{RESULTS OF TEST CASES}

Heat transport and melting have been simulated to seven days for the base case, fast case, and slow melting case. Figure 4 shows the melt shape for all three cases at the final time. Because of radiative heat loss, the soil near the ground surface has solidified, producing a solid cap above the liquid melt. Changing the specific heat of the soil had the most significant affect on the melt volume.

\subsection{Melt Volume Comparison}

Melt boundaries in Figure 4 are for a cross section through the middle of the finite element mesh. These melt boundaries are at seven days into the ISV simulation. The melt boundaries are as expected. For example, a faster melting case has a melt zone that is deeper and wider than a slower melting case. A solid cap is found near the top surface for all cases because of the heat loss by radiation. The solid cap is thickest for the fast melting cases because of the higher thermal conductivity.

Figure 5 shows the melt volume versus time for the base case, fast melting case, and slow melting case. These melt volume plots are second order curve fits to the data produced by VULCAN. The standard error in the curve fits is $2.4 \%$ for the base and fast cases and $1.3 \%$ for the slow case. The melt volumes begin at $3.37 \mathrm{~m}^{3}$, since an initial melted region of this size was used in each case. The simulations all ran for seven days. Figure 6 shows the percentage differences in melt volumes versus time for the fast and slow cases. Percent difference is defined as the fast (or slow) melt volume divided by the base case melt volume. After seven days, the fast melting case had $64 \%$ more soil melted, not counting the original $3.37 \mathrm{~m}^{3}$, and the slow melting case had $40 \%$ less soil melted. Difference between the fast melting case and the base case decreased with time. This decrease in difference is due to the slowing down of the fast melting case as it approaches its final melt volume. The final melt volume is reached when the electrical heat input is equal to the heat lost from the surface by radiation. This simulation did not run long enough to reach this situation.

\subsection{Melt Volume Sensitivity to Soil Parameters}

The melt volume results scale approximately linearly with soil parameter variations. In the following, it is shown that the changes in specific heat are by far the most 

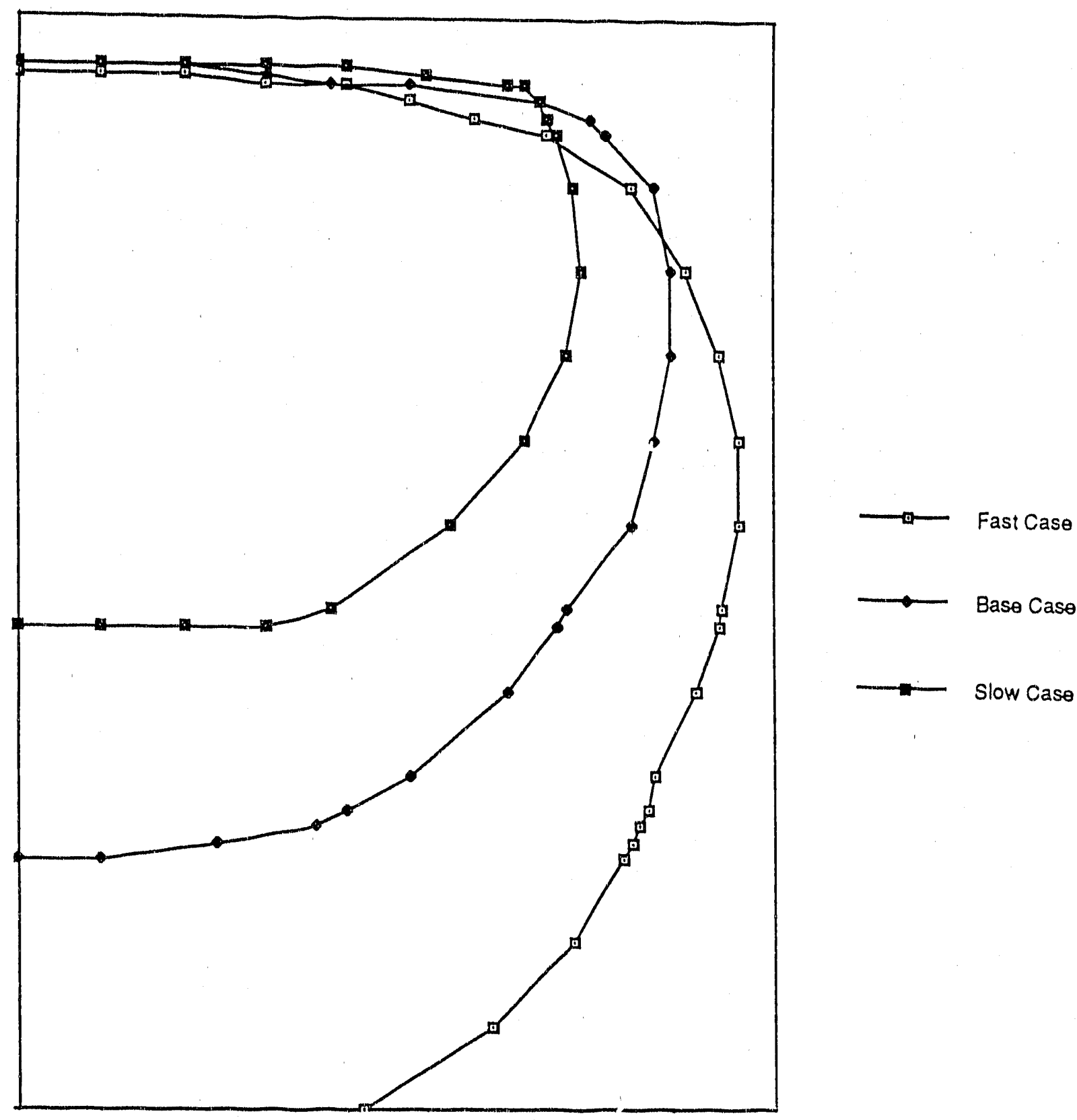

Figure 4. Melt volume cross sections. 


\section{Melt Volumes for Test Cases}

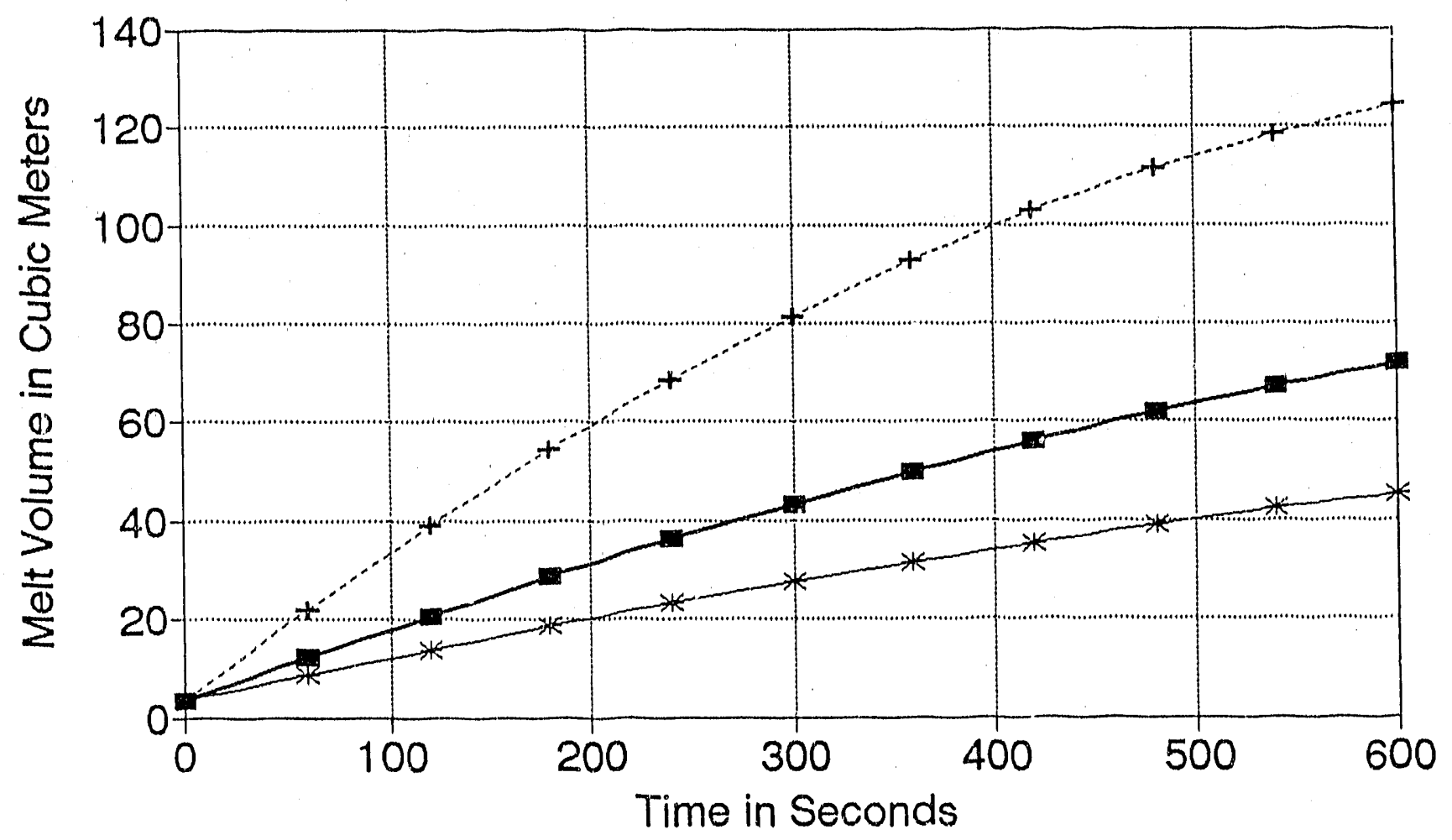

(Thousands)

$\rightarrow-$ Base Case $\quad . .+\cdots$ Fast Melt Case $\rightarrow$ - Slow Melt Case

Figure 5. Melt volumes for basic scenarios. 


\section{Percent Difference in Melt Volume}

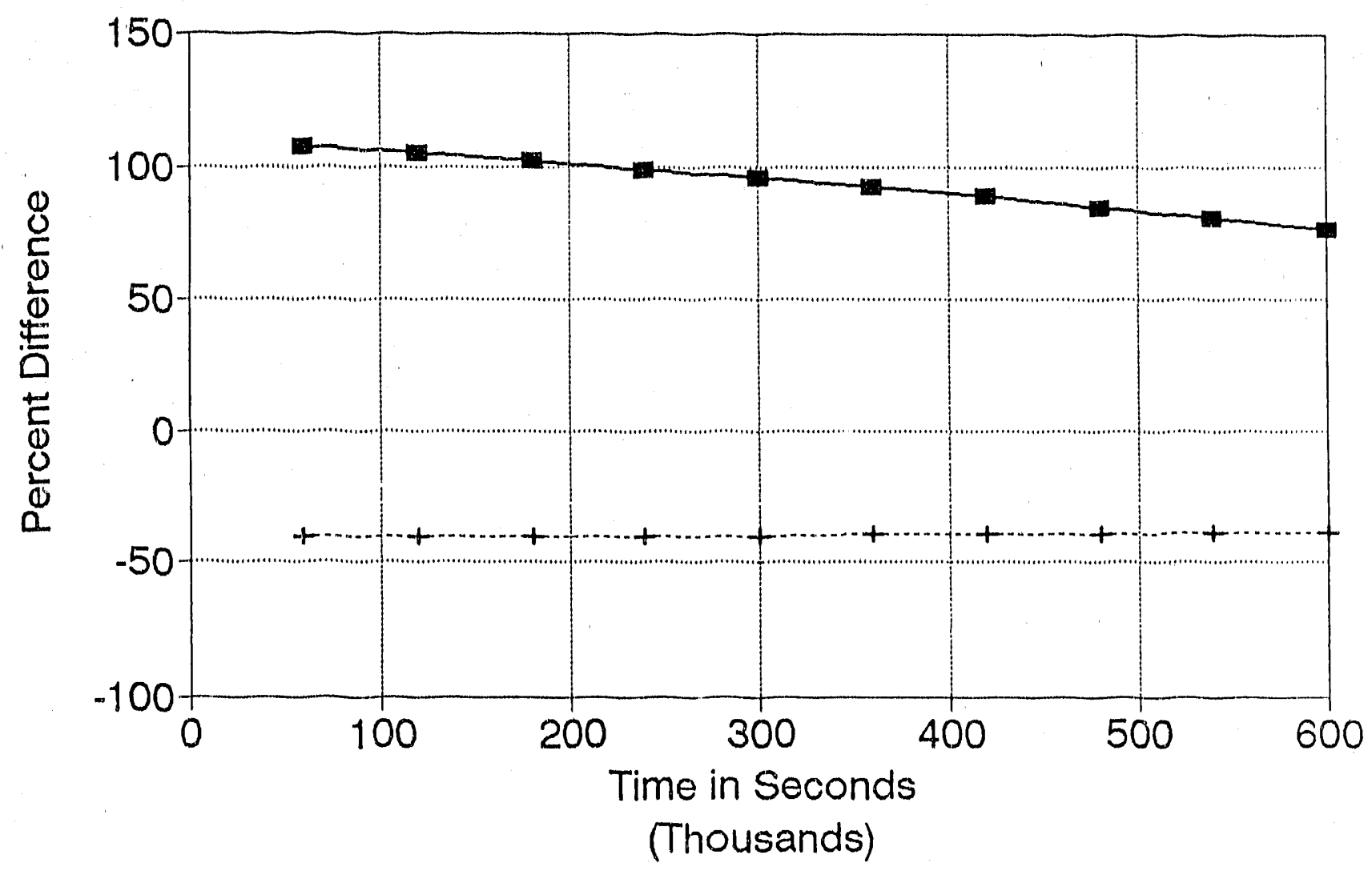

$\rightarrow$ Fast vs Base $\cdots+\cdots$ Slow vs Base

Figure 6. Percent difference in melt volume. 
important in determining melt volume changes. A series of variations on the base, fast melting, and slow thelting cases were run with VULCAN. The variations consisted of increasing, one parameter at a time, the following parameters: specific heat, thermal conductivity, and electrical conductivity by $10 \%$ for all temperatures.

Figure 7 shows the melt volume versus time for the base case and for $10 \%$ increases in specific heat and thermal conductivity. This figure shows the raw data from VULCAN connected by siraight lines. The melt volume changes caused by increasing electrical conductivity are so small that they cannot be seen on the scale of Figure 7. In fact, the change in rnelt volume due to a $10 \%$ increase in electrical conductivity is zero to three decimal places. Melt volume for a $10 \%$ increase in specific heat is obviously lower since it takes more energy to heat each unit of mass. The melt volume for a $10 \%$ increase in thermal conductivity is also lower since the heat is conducted away from the melt faster, and more heat is conducted to the surface to be radiated away. Figure 8 shows the percentage change in melt volume versus time for the specific heat $\therefore$..crease and the thermal conductivity increase. The melt volume change is three times as large for the specific heat increase as for the thermal conductivity increase.

Figure 9 shows the VULCAN melt volume raw data versus time for the fast melting case, and for $10 \%$ increases in specific heat and thermal conductivity. The melt volume changes caused by increasing electrical conductivity are less than $1 \%$ after seven days. Figure 10 shows the percentage change in melt volume versus time based on curve fits of the raw data for the specific heat increase and the thermal conductivity increase. The melt volume change is from about 3 to 10 times larger for the specific heat increase as for the thermal conductivity increase.

Figure 11 shows the VULCAN melt volume raw data versus time for the slow melting case and for $10 \%$ increases in specific heat and thermal conductivity. The melt volume changes caused by increasing electrical conductivity are less than $3 \%$ after seven days. Figure 12 shows the percent change in melt volume vs time for both the specific heat increase and the thermal conductivity increase. The melt volume change is from 6 to about 10 times as large for specific heat increase as for the thermal conductivity increase. The slopes of the curves are not significant compared to the errors in the curve fits used to generate Figure 12.

\subsection{Importance of High and Low Teniperature Values of Soil Parameters}

In the previous studies, soil parameters were changed by the same percentage at all temperatures. To determine the relative importance of high and low temperature changes in soil 


\section{Melt Volume vs Time Base Case}

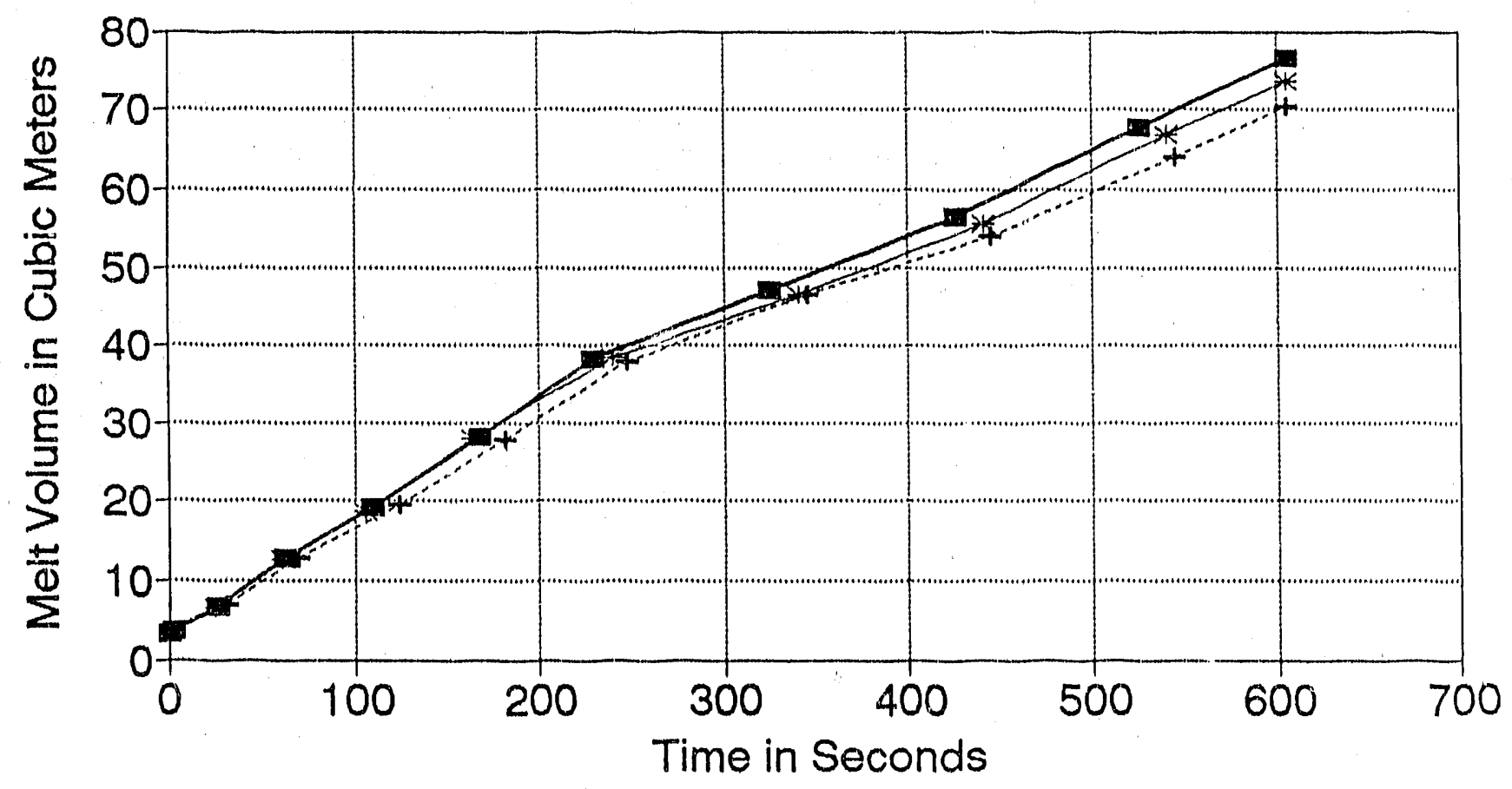

(Thousands)

\section{$\rightarrow-$ Base Case}

$\cdots+\cdots$ Increase in $\mathrm{C}-10 \%$ Increase in $\mathrm{K}$

Figure 7. Variations on base case. 


\section{Change in Melt Volume vs Time Base Case}

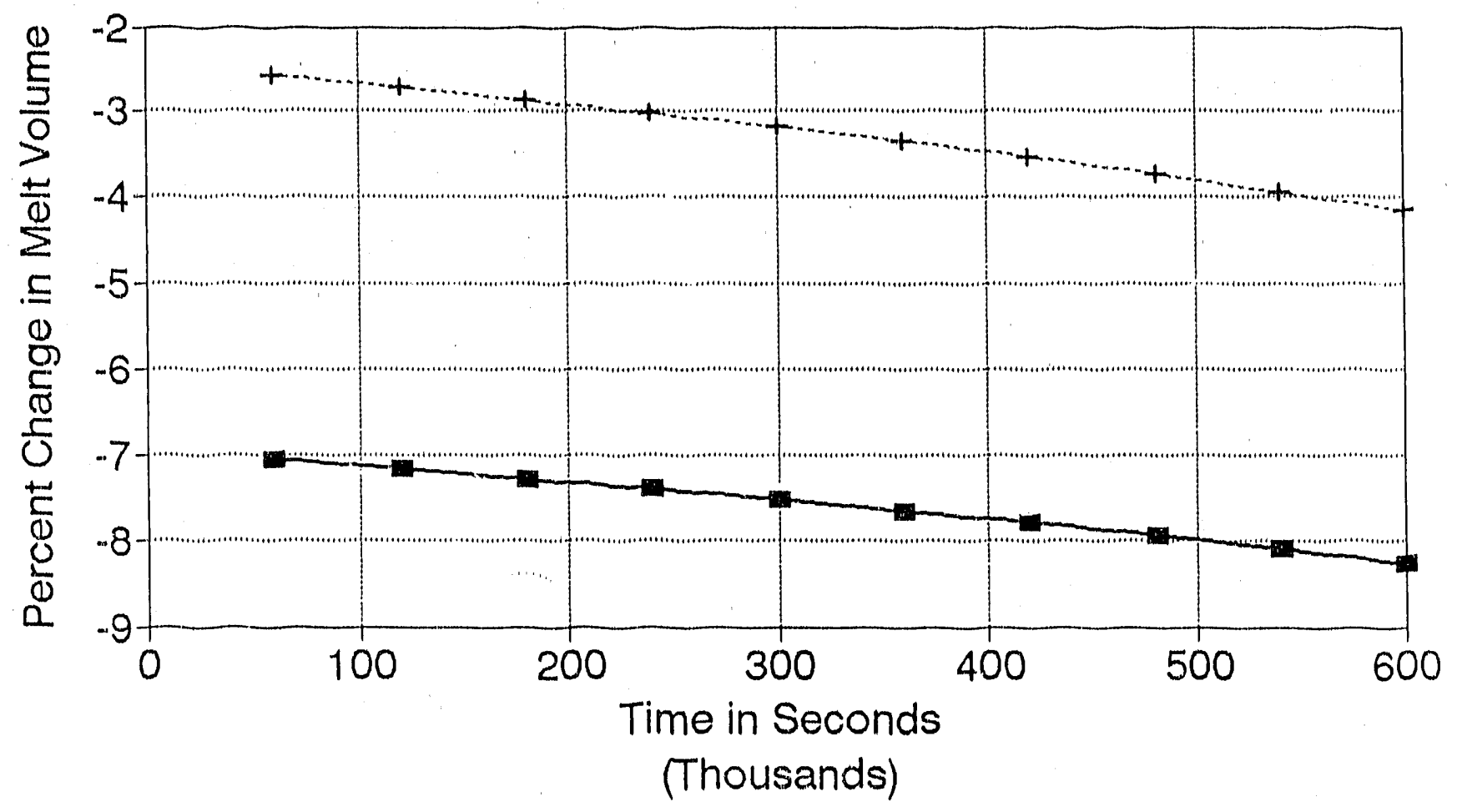

$\rightarrow-10 \%$ Increase in $\mathrm{Cp} \cdots+\cdots 10 \%$ Increase in $\mathrm{K}$

Figure 8. Change in melt volume for base case. 


\section{Melt Volume vs Time Fast Melting Case}

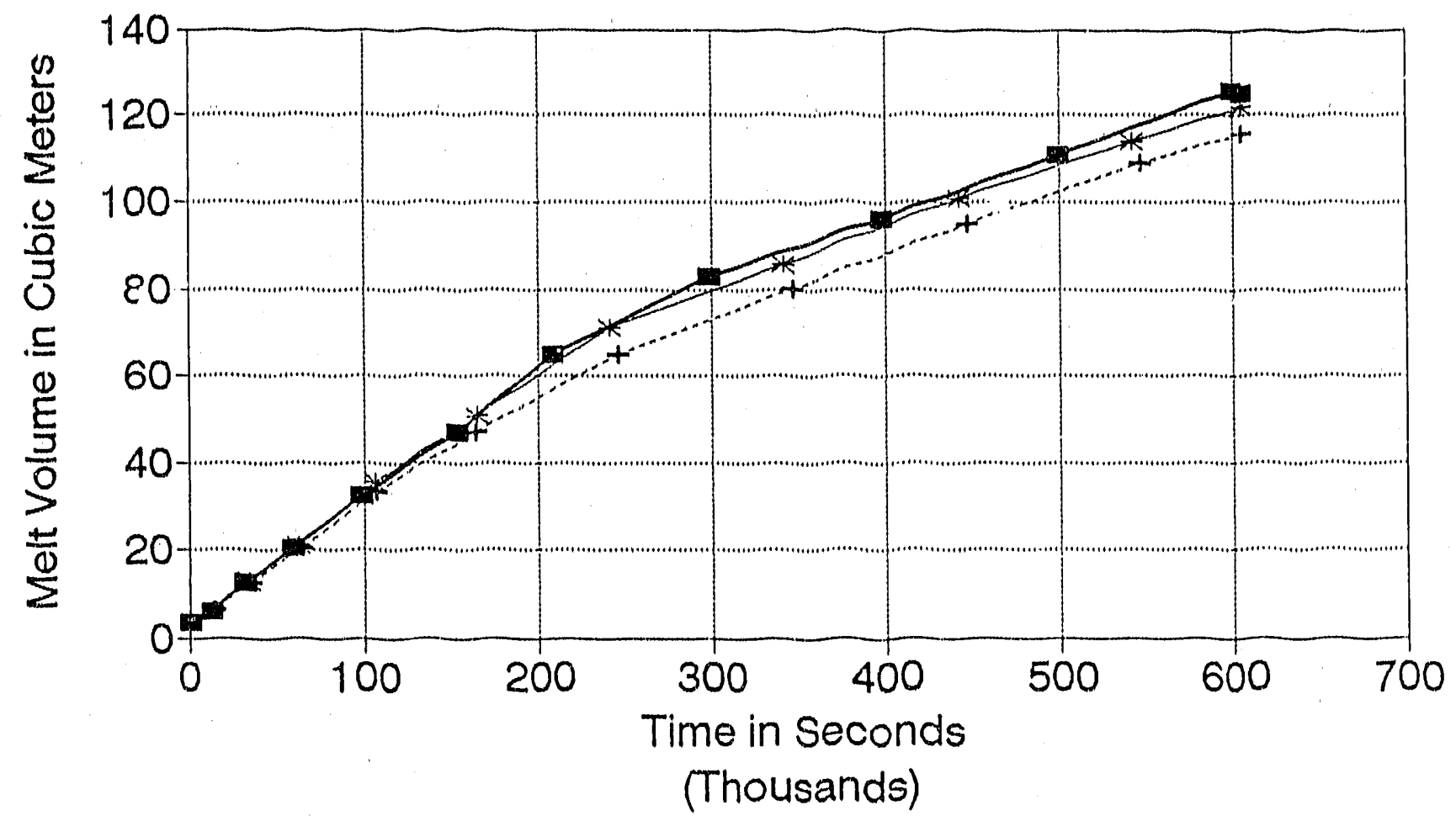

$\rightarrow-$ Basic Fast Melting $\cdots+\cdots 10 \%$ Increase in $\mathrm{C} \rightarrow 10 \%$ Increase in $\mathrm{K}$

Figure 9. Variations on fast melting case. 


\section{Change in Melt Volume vs Time Fast Melt Case}

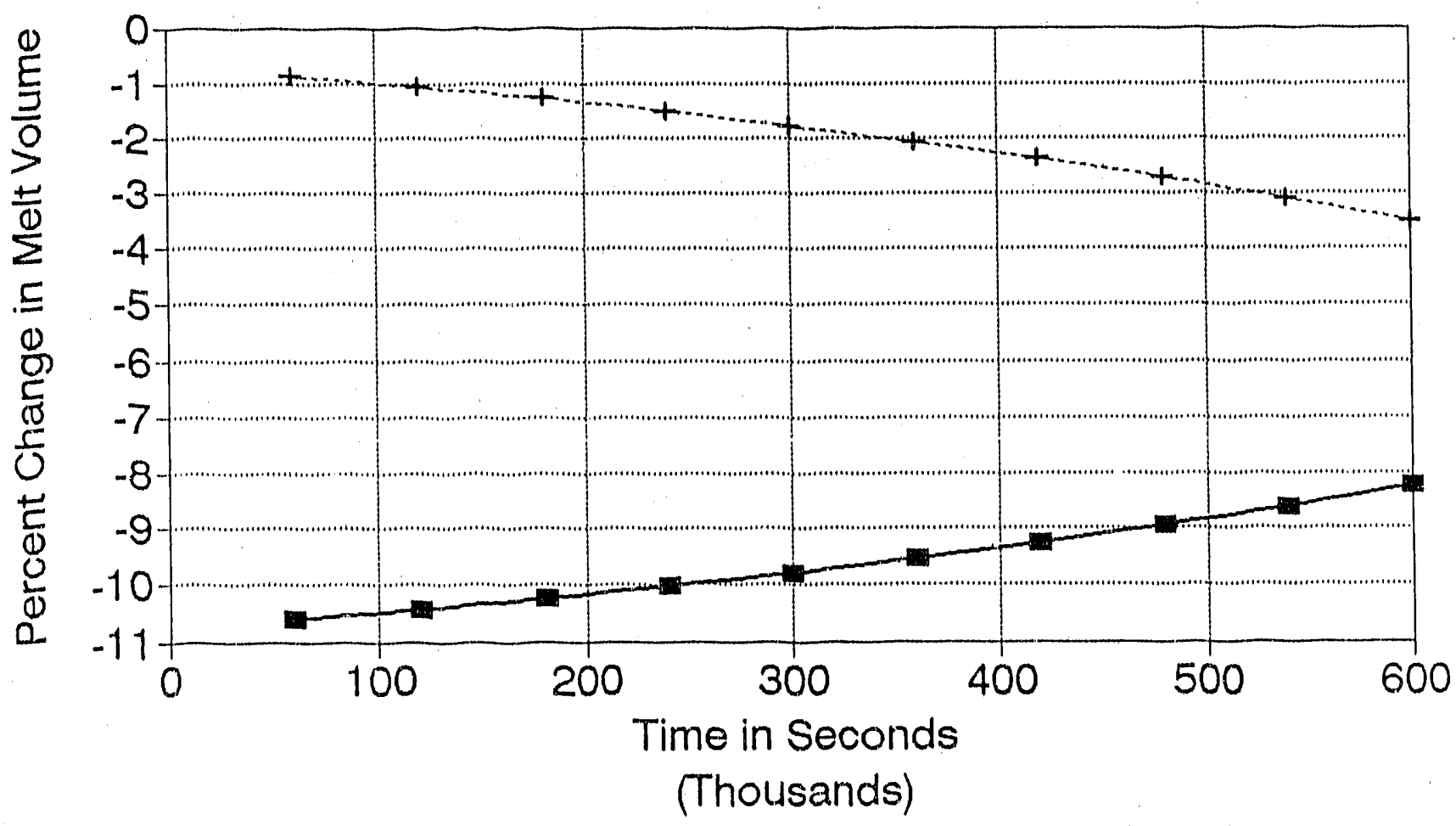

$\rightarrow-10 \%$ Increase $\mathrm{Cp} \cdots+\cdots 10 \%$ Increase in $\mathrm{K}$

Figure 10. Change in melt volume for fast melting case. 


\section{Melt Volume vs Time Slow Melting Case}

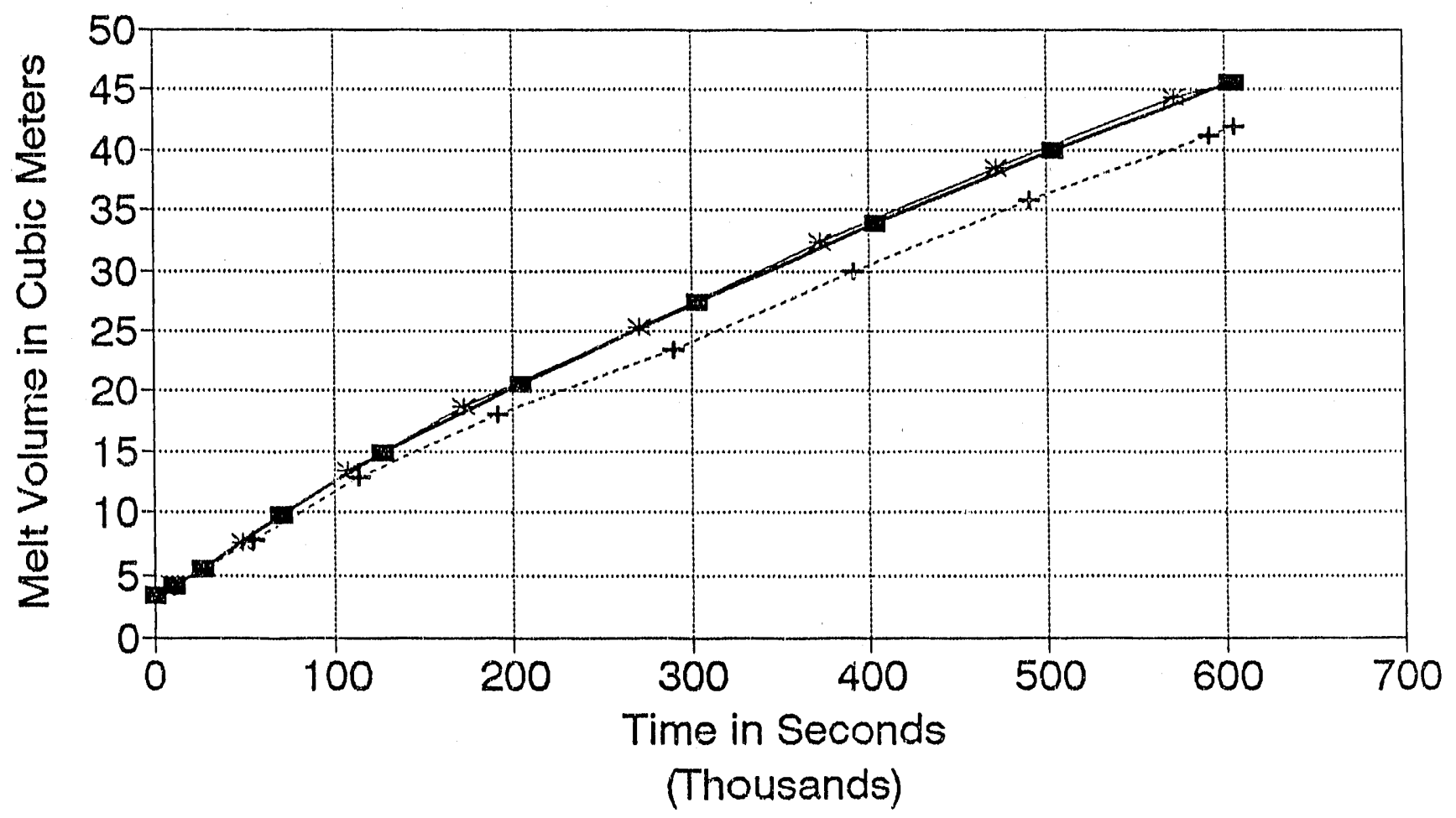

$\rightarrow-$ Basic Slow Melting $\cdots+\cdots 10 \%$ Increase in $\mathrm{C} \rightarrow 10 \%$ Increase in $\mathrm{K}$

Figure 11. Variations on slow melting case. 


\section{Change in Melt Volume vs Time Slow Case}

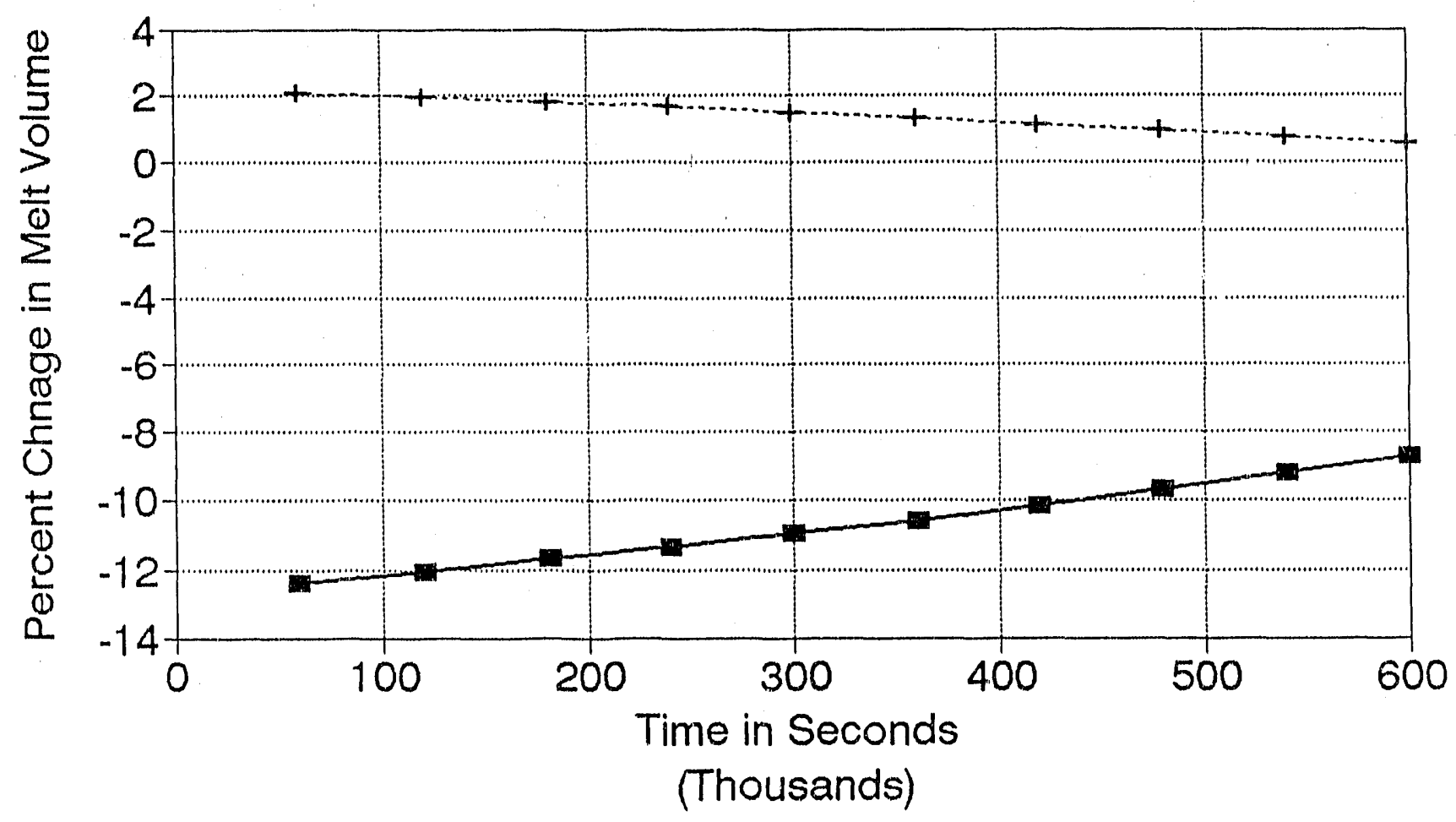

$\rightarrow-10 \%$ Increase in $\mathrm{Cp} \cdots+\cdots 10 \%$ Increase in $\mathrm{K}$

Figure 12. Change in melt volume for slow melting case. 
parameters, a series of runs were made. High temperatures were defiried to be above the melting point of soil and low temperatures were defined to be those below the melting point.

For thermal conductivity, the low temperature values are most important. When low temperature thermal conductivity is increased by $10 \%$, for the base case, melt volume decreases from $19.1 \mathrm{~m}^{3}$ to $18.3 \mathrm{~m}^{3}$. But when high temperature thermal conductivity is increased by $10 \%$, melt volume increases slightly to $19.2 \mathrm{~m}^{3}$.

For specific heat, both high and low temperature values are almost equally important. When low temperature specific heat is increased by $10 \%$ for the base case, the melt volume decreases to $17.3 \mathrm{~m}^{3}$. When high temperature specific heat is increased $10 \%$, the melt volume decreases to $17.9 \mathrm{~m}^{3}$. 


\section{CONCLUSIONS}

Numerical calculations have been performed for two finite element models in support of ISV calculations. A series of parametric studies on heat transport and soil melting with changes in soil properties has been performed. Results indicate that changes in the specific heat have the most significant affect on the simulations. The melt volume is less sensitive to thermal conductivity changes. Changes with electrical conductivity are not important in most cases.

Thermal conductivity values at low temperatures are more important when considering melting rates than thermal conductivity values at high temperatures. The low temperature thermal conductivity values are indicative of the insulating effectiveness of the solid soil surrounding the melted soil. Specific heat values at both high and low temperatures are important when considering melting rates. 


\section{REFERENCES}

1. PDA Engineering, PATRAN Plus User Manual, Version 2.3, PDA Engineering, Costa Mesa, California, July 1988.

2. P. E. Murray and M. O. Fryer, Simulation of Heat Conduction and Electric Fields During In Situ Vitrification of Soil: Method Design and Verification, EGG-WM-9045, September 1990.

3. J. L. Buelt et al., In Situ Vitrification of Transuranic Waste: An Updated Systems Evaluation and Applications Assessment, PNL-4800 Supplement 1, March 1987. 



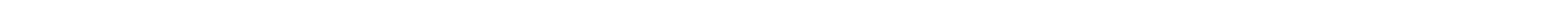

